Dhaka Univ. J. Biol. Sci. 23(1): 39-45, 2014 (January)

\title{
IMPACT OF PSYCHO-EDUCATION ON CARE GIVERS MENTAL HEALTH AND PERCEIVED STRESS OF CHILDREN WITH AUTISM
}

\author{
Jesan Ara ${ }^{1}$ and Kamal Uddin Ahmed Chowdhury \\ Department of Clinical Psychology, University of Dhaka, Dhaka-1000, Bangladesh
}

Key words: Psycho-education, Care givers, Mental health, Autism

\begin{abstract}
The purpose of the study was to assess the impact of psycho-education on care givers mental health and level of stress. The study attempts to increase knowledge about autism in addition to reduce stress and disturbances of mental health condition among care givers of children with autism. Pre-post design was used to assess the perceived stress and mental health condition of the participants. The control group did not receive the psycho-education session and the experimental group received the psycho-education session. During the pretest all measures were administered and in post-test session all measures were re-administered to the experimental group and the control group. During postintervention phase, a significant improvement in care givers' perceived stress and mental health condition (except severe depression) was noted in the experimental group. But condition of the care givers of the control group who did not receive psycho-education remained the same for the same variables. Results suggested that psycho-educational intervention is effective in increasing knowledge regarding the condition and in meeting the needs of the care givers of children with autism spectrum disorders.
\end{abstract}

\section{Introduction}

Autism is a complex condition and a group of developmental brain disorders that impacts normal brain development. It is also a spectrum disorder. Autism can be defined at three different interdependent levels: as a neurological disorder related to brain development; as a psychological disorder of cognitive, emotional, and behavioral development; or as a relationship disorder in which there is a failure of normal socialization $^{(1)}$.

Current research suggests that there may be a definite increase in the incidence of autism spectrum disorders (ASD) all over the world. In a 2007 government survey on ASD prevalence, the Centers for Disease Control and Prevention (CDC) found that the rate of ASD was higher than in past U.S. studies. However, there is no national epidemiological study on autism in Bangladesh. A research was done during the period

\footnotetext{
${ }^{1}$ Author for correspondence: <jesan53006@gmail.com>.
} 
of July to December 2009 in 50 randomly (25 urban and 25 rural) selected clusters of Dhaka division. Adjusted prevalence rate of autistic disorder was found as $0.8 \%$. Distributions of prevalence of individual with autistic disorder in male were $63.3 \%$ and female were $36.4 \%{ }^{(2)}$.

In Bangladesh the family members are closely attached to each other and care giving is a common social role here. Families, which live separately, also keep close contact with their relatives. When a family member becomes sick, the whole family literally looks after the person. When family members assume the care giving role, it is likely that they will suffer increased level of anxiety, depression, distress and mental health problem ${ }^{(3,4)}$. A child with autism is a large stressor on the care givers because of the ambiguity of diagnosis, the severity and duration of the disorder, and problems with the child's lack of adherence to social norms ${ }^{(5)}$. Accurate knowledge of autism may aid care givers in relating to their children's difficult behavior. Reading up on and accepting autism may promote feelings of care giving success.

Due to the significantly different ranges of symptoms presented in individuals with ASD, it may be challenging for care givers and professionals to decide on one of many treatment options that are available. Psycho-education is a specific form of education. Psycho-education is a general term for an educational approach of assistance to offer accurate knowledge and information about the nature and methods of treatment ${ }^{(6)}$. It is also addressing the disease needed for cure added with consideration for psychotherapy. Moreover, elaborated psycho-educational program will ensure the healthy family environment that has good communication and problem-solving skills and coping strategies dealing with autistic individuals. These skills and strategies minimize the risk of poor illness management on the part of the caregivers.

In Bangladesh there is an increase in the number of children with autism. There are many organizations and institutions that are working with children with autism but even that day the general attitude towards autism is negative most of the time and it is seen as a social barrier. It is evident that in Bangladesh mothers of children with intellectual disability were more dominating, showed overprotection, and hoped for a miraculous cure and relied on fate( ${ }^{(7)}$. These happen because of care givers lack of information about autism and lack of care giving skills to interact with these children. Researchers suggested that gaining the cooperation of care giver is important, since they play a vital role in the treatment of autism, and their active involvement is essential for the success of any intervention ${ }^{(8)}$. So, there is a great need to develop psycho-education materials for the care givers of children with autism so that care givers can understand the nature and extent of autism and can learn skills and strategies to interact with these children as effectively as possible. The present study has been designed to meet this important need in Bangladesh. 


\section{Materials and methods}

Initially 40 care givers of children with autism were selected using purposive sampling technique from two special schools of autism of Dhaka City. The care givers were equally matched according to age, sex, education, income, structure of family etc. and they were divided into two groups - the experimental group (20), and the control group (20). The demographic characteristic of the final sample is given in Table 1.

Table 1. Characteristics of care givers of children with autism.

\begin{tabular}{|c|c|c|c|}
\hline Characteristics & & $\begin{array}{c}\text { Experimental group } \\
(\mathrm{n}=20)\end{array}$ & 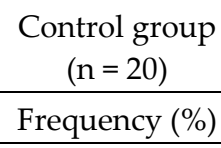 \\
\hline \multirow{3}{*}{ Sex } & Male & $0(0)$ & $0(0)$ \\
\hline & Female & $20(100)$ & $20(100)$ \\
\hline & 18 - 28 years & $1(5)$ & $2(10)$ \\
\hline \multirow[t]{4}{*}{ Age } & 29 - 39 years & $11(55)$ & $11(55)$ \\
\hline & $40-49$ years & $8(40)$ & $7(35)$ \\
\hline & Below SSC & $1(5)$ & $0(0)$ \\
\hline & SSC-HSC & $3(15)$ & $4(20)$ \\
\hline \multirow[t]{2}{*}{ Education } & Graduate - Post-graduate & $16(80)$ & $16(80)$ \\
\hline & House wife & $18(90)$ & $17(85)$ \\
\hline \multirow[t]{3}{*}{ Occupation } & Service holder & $2(10)$ & $2(10)$ \\
\hline & Business & $0(0)$ & $1(5)$ \\
\hline & below 10,000 Tk & $1(5)$ & $1(5)$ \\
\hline \multirow[t]{4}{*}{ Family income } & 10001 to $20000 \mathrm{Tk}$ & $2(10)$ & $2(10)$ \\
\hline & 20001 to $40000 \mathrm{Tk}$ & $13(65)$ & $12(60)$ \\
\hline & 40001 Tk to above & $4(20)$ & $5(25)$ \\
\hline & Married & $20(100)$ & $19(95)$ \\
\hline \multirow[t]{2}{*}{ Marital status } & Unmarried & $0(0)$ & $1(5)$ \\
\hline & Others & $0(0)$ & $0(0)$ \\
\hline \multirow[t]{2}{*}{ Structure of family } & Nuclear family & $17(85)$ & $16(80)$ \\
\hline & Extended family & $3(15)$ & $4(20)$ \\
\hline
\end{tabular}

The Perceived Stress Scale (PSS) was designed by Cohen and his associates in 1983 to measure the degree to which situations in one's life are appraised as stressful. The reliability of the PSS was 0.85 and 0.55 . Concurrent validity and prediction was found and Cronbach's alpha was found 0.75 . Thus the face validity of the scale was determined. The correlation between the two versions was found. 
To assess the general emotional disturbances the General Health Questionnaire (GHQ-28), was administered. This 28-item checklist assesses the psychological disturbances in terms of both a full-scale score (maximum possible score $=84$ ) and it has four sub scales, reflecting somatic symptoms, anxiety and insomnia, social dysfunction and severe depression. It has been shown to have test-retest reliability from 0.51 to 0.90 and the split-half reliability was shown to be 0.95 . GHQ-28 was shown to have construct, content and concurrent validity. Banoo translated it into Bangla ${ }^{(9)}$. The test-retest reliability was found to be 0.682 by Spearman's rho, which was significant at 0.01 level.

Psycho-education material (Bangla version) used in this study was developed by the researcher herself. From the first judge evaluation to the final write up was done between February, 2012 and April, 2012. Psycho-education of the present study included many areas - a general introduction on autism, i.e. common symptoms, the etiology, available treatment, prognosis, information about food, daily activity, recreational activity, task analysis, how to behave with these children, what should be done if child become violent and demanding or calm, uses of reinforcement, how to manage while looking after the child, etiological and triggering factors like stress, understanding their situation, how to provide them with support, coping strategies etc.

The participants for this study were selected after obtaining necessary approval from the authorities. Data collection was conducted from May to August 2012 in official settings of the specific schools. Forty caregivers initially completed the self-administered measuring instruments: Perceived stress scale and GHQ-28. The care givers assigned to the experimental group received a psycho-educational intervention after the pre-test whilst the care givers assigned to the control group did not receive any specific intervention. The psycho-education session of experimental group was completed three sessions and two hours duration $(3 \times 2 \mathrm{hrs})$ for each care giver separately. After four weeks of completing the psycho-education session the participants were again interviewed and all measures were re-administered.

\section{Results and Discussion}

In order to investigate the impact of psycho-education on care givers of children with autism, paired comparison $t$ test was used to determine the significant difference between two groups. P-values less than 0.05 were considered to indicate statistical significance. Firstly a comparison was made between the experimental and the control group with regard to the means of their pre-test scores.

The aim of the present study was to find out the impact of psycho-educational intervention for care givers of children with autism spectrum disorders. However, as expected, results showed that care givers who received psycho-educational interventions showed significant reduction in the score of mental health disturbance on the GHQ-28 except 'severe depression' than those who did not (Table 3). 
Table 2. Comparison between the means of obtained scores from the pre-test session of the experimental group and first session of the control group in respect of perceived stress scale (PSS) and sub-scales of GHQ-28.

\begin{tabular}{lcccccc}
\hline \multirow{2}{*}{ Variable } & $\begin{array}{c}\text { Maximum } \\
\text { possible } \\
\text { score }\end{array}$ & \multicolumn{2}{c}{$\begin{array}{c}\text { Experimental } \\
\text { group }\end{array}$} & \multicolumn{2}{c}{ Control group } & \multirow{2}{*}{ t value } \\
\cline { 3 - 6 } & & Mean & SD & Mean & SD & \\
\hline PSS & 56 & 24.55 & 4.74 & 24.90 & 6.09 & 0.20 \\
GHQ-28 & 84 & 35.40 & 9.77 & 33.95 & 11.11 & 0.551 \\
A - somatic symptoms & 21 & 10.00 & 3.55 & 9.05 & 4.16 & 1.105 \\
B - anxiety and insomnia & 21 & 9.10 & 3.09 & 8.50 & 3.02 & 0.834 \\
C - social dysfunction & 21 & 10.20 & 3.002 & 9.70 & 3.097 & 0.534 \\
D - severe depression & 21 & 6.10 & 4.44 & 6.70 & 4.61 & 0.403 \\
\hline
\end{tabular}

Table 3 shows a significant improvement in total of GHQ-28 $\left(t=2.88,{ }^{* *} \mathrm{p}<0.01\right)$. Significant improvement also reported in sub-scales of GHQ-28 - somatic symptoms $(t$ $\left.=2.12,{ }^{*} \mathrm{p}<0.05\right)$, anxiety and insomnia $\left(\mathrm{t}=2.14,{ }^{*} \mathrm{p}<0.05\right)$, social dysfunction $(\mathrm{t}=3.01$, $\left.{ }^{* *} \mathrm{p}<0.01\right)$. But in case of perceived stress and severe depression no significant difference was found.

Table 3. Comparison between the means of obtained scores from the post-test session of the experimental group and second session of the control group in respect of sub-scales of GHQ-28 and perceived stress scale (PSS).

\begin{tabular}{|c|c|c|c|c|c|c|}
\hline \multirow{2}{*}{ Variable } & \multirow{2}{*}{$\begin{array}{c}\text { Maximum } \\
\text { possible score }\end{array}$} & \multicolumn{2}{|c|}{ Experimental group } & \multicolumn{2}{|c|}{ Control group } & \multirow[t]{2}{*}{ t value } \\
\hline & & Mean & SD & Mean & SD & \\
\hline PSS & 56 & 20.25 & 5.21 & 23.70 & 6.09 & 1.76 \\
\hline GHQ-28 & 84 & 26.65 & 9.73 & 34.25 & 9.92 & $2.88^{* *}$ \\
\hline A - somatic symptoms & 21 & 7.10 & 3.74 & 9.35 & 4.49 & $2.12^{*}$ \\
\hline B - anxiety and insomnia & 21 & 7.30 & 3.23 & 9.05 & 3.38 & $2.14^{*}$ \\
\hline C - social dysfunction & 21 & 7.60 & 1.79 & 9.85 & 2.50 & $3.01^{* *}$ \\
\hline D - severe depression & 21 & 4.65 & 3.82 & 6.00 & 4.18 & 1.01 \\
\hline
\end{tabular}

${ }^{* *} \mathrm{p}<0.01,{ }^{*} \mathrm{p}<0.05$.

Analysis of the results was also carried out to see if it can produce any change in the severity level of the mental health condition. It can be seen from Table 3 that according to GHQ-28 scores the general mental health of early half of these care givers in experimental group $9(45 \%)$ and in control group $8(40 \%)$ caused concern. In post-test session of experimental group mental health disturbances were lessened and only 2 $(10 \%)$ care givers were at clinical level. These participants were shown to benefit from 
psycho-educational intervention compared to the control group. The results of control group were totally different. Because nearly same 7 (35\%) of the care givers of the control group, respectively were assessed as having the problems at clinical level.

This study provides evidence that psycho-educational intervention for care givers of children with autism were beneficial to their mental health and well-being. Table 3 shows that in post intervention phase, the psycho-educational intervention was effective in alleviating a greater percentage of somatic symptoms, anxiety and insomnia, and social dysfunction of experimental group. The results confirmed that most of the care givers of control group did not know how to manage their children. They continued to manage their children as they had managed them previously and felt irritated which resulted in increasing their problems. So, no significant difference was found between the first and second sessions of that group for the mentioned variables. The results found from GHQ28 also support this interpretation. It can be concluded that initial recognition of a symptom and sustained awareness of the child's behavior are critical for intervention since they serve as a window for immediate and more effective treatment. This argument is supported by more oriented interventions showing positive effect on parents with $\operatorname{ASDs}^{(10)}$.

Moreover, no significant difference was found between the control and the experimental group in severe depression (Table 3). The heterogeneity of mean scores relating the post-test score to the pre-test score implies that the effect of treatment is dependent on level of depressive symptomatology at pre-test. A possible reason is the slightly change of depression, which responds slightly to the presence of social support or educational strategy but requires effective treatment. The findings of this study are also in conformity with previous studies ${ }^{(11)}$.

Most of the care givers reported not being able to pursue social, recreational or leisure interests, such as family excursions, time with their partners, their other children or friends and burden of care. Care givers also reported that when they are stressed, they can become easily irritated and frustrated. These limitations were recognized by researcher and stress levels were high amongst these care givers. So, there is a need for further comprehensive study to explore their stress, and proper program should be applied to help them managing their stress.

The children whose care givers attended the intervention group experienced improvements in mental health conditions compared to those of the control group. The present study concludes that psycho-educational intervention is effective in teaching the care givers to manage their children with autism and it is also effective in enhancing the caregivers' quality of life. 


\section{References}

1. Kusch M and F Petermann 1995. Pervasive Developmental Disorders. In: Developmental Psychology (Ciccetti D and D Cohen Eds.), pp. 177-218. New York: Wiley.

2. Rabbani MG, MF Alam, HU Ahmed, M Sarker, WA Chowdhury and MM Zaman 2009. Prevalence of mental disorders, mental retardation, epilepsy and substance abuse in children. Bang. J. Psychat. 23: 13-54.

3. Yirmiya $\mathrm{N}$ and $\mathrm{M}$ Shaked 2005. Psychiatric disorders in parents of children with autism: a meta analysis. J. Child Psychol. Psychiatry 46: 69-83.

4. Tunali B and T Power 2002. Coping by redefinition: cognitive appraisals in mothers of children with autism and children without autism. J. Autism Dev. Disord. 32: 25-34.

5. Bristol MM 1984. Family resources and successful adaptation to autistic children. In: The effects of autism on the family (Schopler E and GB Mesibov Eds.), pp. 289-310. New York, Plenum Press.

6. Oshima I 1993. Psycho-education. In: New Psychiatry Dictionary (Kato M Ed.), p. 414. Kobundo, Tokyo.

7. Zaaman SS and N Rahman 1982. A comparative study of attitudes and personality traits of mothers of mentally retarded children with and without intervention. Dhaka Univ. J. Psychol. 12: 33-49.

8. Lord C and M Rutter 1994. Autism and Pervasive Developmental Disorders. In: Child and Adolescent Psychiatry (Rutter M, E Taylor and L Hersov Eds.),3rd edition, pp. 569-593, Boston, Blackwell Scientific Publications.

9. Banoo SN 2001. Stress and Burden of the caregivers of Chronic Mental Adult Patient. M.Sc. Thesis, Department of Clinical Psychology, University of Dhaka.

10. Green J, T Charman and A Pickles 2010. Parent-mediated communication-focused treatment in children with autism (PACT): A randomised controlled trial. Lancet. 19: 375(9732): 21522160.

11. Davis and AS Carter 2008. Parenting stress in mothers and fathers of toddlers with autism spectrum disorders: associations with child characteristics. J. Autism Dev. Disord. 38(7): 1278-1291. 